\title{
Bird community as an indicator of biodiversity: results from quantitative surveys in Brazil*
}

\author{
JACQUES M. E. VIELLIARD** \\ Instituto de Biologia, UNICAMP, Dept. de Zoologia, Cx. Postal 6109 - 13083-970 Campinas, SP, Brazil \\ Manuscript received on May 15, 2000; accepted for publication on May 19, 2000.
}

\begin{abstract}
This short review presents the results obtained in several localities of Brazil on the composition of forest bird communities. Data were collected since the late 80's, after we introduced a new methodology of quantitative survey, based on acoustic identification and unlimited-radius point census. Although these data are still scattered, they show uniquely precise and coherently comparative patterns of composition of forest bird communities. Our methodology has the advantage of being absolutely non-disturbing, highly efficient in the field and immediately processed. Results confirm that the structure of a bird community is a good indicator of biodiversity, particularly useful where biodiversity is high. Many of these data are available only in unpublished dissertations and abstracts of congress communications, or are being analysed. A cooperative program is needed to promote new surveys and publish their results, as a contribution for measuring and monitoring biodiversity, especially in complex endangered habitats.
\end{abstract}

Key words: birds, community, census, Brazil, biodiversity, conservation.

\section{HISTORICAL BACKGROUND}

\section{The CONSERVATION OF BIODIVERSITY}

The world-wide destruction of tropical forests has awakened, during the last few decades, a sense of urgency for their preservation. That situation has recently become a high priority, thanks to public awareness of the huge biodiversity and fragility of these ecosystems. Unfortunately, scientists and conservationists find themselves now in a desperate need to present data, which could help save what is left of these threatened natural resources.

\footnotetext{
To the memory of Carlos Chagas Filho, founder of the Instituto de Biofísica/UFRJ, where I introduced bioacoustic technics at the invitation of the late Aristides A. P. Leão and with the help of Carlos Eduardo-G. da Rocha Miranda, Eduardo Oswaldo Cruz, Ricardo Gattass and Monsieur Raymundo.

* Invited paper

**Foreign Member of the Academia Brasileira de Ciências E-mail: jacques@unicamp.br
}

Because the simple inventory of tropical biodiversity has been neglected since the turn of this century and is still emerging from its perceived state of "poor" science, a special effort is required to gather as quickly as possible the data thought to be most needed to efficiently direct the urgent preservation and management of tropical forests.

With this situation in mind, some scientists have turned their efforts to research aimed at the description and understanding of tropical forest ecosystems, using innovative approaches in various fields. As the present review is related to birds, and these are a material of choice for the study of ecosystems, we will refer in this paper only to ornithological contributions, of which we recognize four distinct strategies:

1) Some, like Prum (e.g. 1994), reevaluate species limits, helping to define accurately 
these evolutionary units and to understand better their interaction in the community.

2) Others, like the late Ted Parker (references in Stotz et al. 1996), implement field survey methodologies, aimed at the quick gathering of data to be used for conservation policy: this is the "Rapid Assessment Program-RAP" developed for Conservation International.

3) Still others, like Haffer (1974) or Brown (1986), use biogeographical analysis for a definition of priority areas for preservation.

4) A fourth approach is the ecological study of communities, which is highly demanding in terms of field research, but essential for understanding the effects of habitat alterations and for planning efficient management. The greatest effort made in this direction is the Minimum Critical Size of Ecosystems, now Biological Dynamics of Forest Fragments Project developed since 1979 in the Amazonian region near Manaus, producing a wealth of original data (e.g. Bierregaard \& Lovejoy 1989, Stouffer \& Bierregaard 1995).

\section{Bird COMmunities}

It is well accepted that a bird community reflects the whole biodiversity of its habitat. However, as we do not know even the number of species of most organisms existing in a complex ecosystem, we are reduced to presumptions. This is especially true in tropical forests, the richest and most endangered habitat on earth. That is why we turn to birds to try to get an indicator of biodiversity, not necessarily perfectly accurate, but easily available.

Since 1973, through the leadership of the Brazilian Academy of Sciences, the establishment of a methodology for assessing and monitoring natural ecosystems became a priority in Brazil. After a long period of data gathering and method testing, our first results were obtained in 1984 (Vielliard \& Silva 1990a). This was followed by the production of a still small data base on a few localities, mostly in the Southeastern Atlantic Forest of the São Paulo, Paraná and Santa Catarina States (Anjos 1992, Barbosa 1992, Toledo 1993, Aleixo \& Vielliard 1995, Aleixo 1996, Machado 1996, Almeida et al. 1999, Vielliard \& Silva in press).

Most of these data must be extracted from theses and congress communications, or are still awaiting analysis. We will present in this review results of the analyses currently concluded, although not always fully published yet. References mentioned in the text, but not shown in the table, are still needing data analysis and calculation.

\section{ACOUSTIC IDENTIFICATION}

The Laboratory of Ornithology and Bioacoustics, which was created at the Campinas State UniversityUNICAMP in 1978, has concentrated its efforts to establish the data base and the methodology needed to achieve these purposes. The idea was to use acoustic characters for field identification in real time, and standardize censuses based on such identifications for calculating indices allowing objective evaluation and monitoring of bird communities.

If one accepts bird community structure as the best estimate or the most representative of the whole ecosystem, this could be the only available methodology able to obtain such results in tropical forest without delay or disturbance.

The first step was to create a representative sound archive of the voices of all bird species expected in the area to be covered, i.e. the whole of Brazil. Although it seemed to be an impossible task, I made the "Arquivo Sonoro Neotropical" at UNICAMP into one of the major wildlife sound libraries of the world (see Kettle 1989). This sound archive was made by the recordings I gathered in the field since 1973 thanks to the support of the Brazilian Academy of Science-ABC and the National Council of Research-CNPq, and recordings contributed by many colleagues, mainly keen amateurs like José Carlos Reis de Magalhães, Johan Dalgas Frisch, Gérard Baudet, Anita Studer, Dante Buzetti and the late Aristides Azevedo Pacheco Leão, who labelled himself proudly as an amateur ornithologist, and was 
in fact a pioneer in bird voice field-recording.

These efforts and ample collaboration permitted us to be fully operational in the field in most regions of Brazil from the mid-80s. Thus we had an opportunity to take the second step: testing census methodology.

\section{Point Census}

Our first attempt was undertaken in a relatively small forest remnant in the interior of São Paulo State (Vielliard \& Silva 1990a,b), and proved to be highly efficient, once a reliable sound archive had been assembled, as we had done. The area and the financial support to test our methodology were provided by Duratex S.A., as part of its program of biodiversity monitoring.

Since my first trip in Brazil, at the invitation of the Brazilian Academy of Sciences in 1973, I had in mind to apply the point census method which had been developed recently in France after long discussions and tests (Blondel et al. 1970). It gave the advantage to permit representative sampling in heterogenous habitat. Unlike other methods, transects, quadrats or mist-nets, it does not require large time investment either in preparation or execution (review in Ralph \& Scott 1981). However, it was necessary to adapt the parameters of the census method to the particular conditions of bird life in tropical forests, such as high number of species, low density of most of them, variety of spatial distribution patterns and of social organization, and asynchronous breeding cycles. This is where point censuses have shown their principal advantage: the ease by which they can be repeated and spread over the area and seasons, because they are not very much time-consuming.

Consequently, the same methodology has been employed, after we made it public, for as many localities as possible. As previously stated, most of the data were gathered in the Southeastern part of the Atlantic Forest, but good results were obtained also in the Amazonian Forest, although they have not been published because these surveys were interrupted before completion for lack of funds.

The censusing method, which is explained in details in Vielliard \& Silva (1990a) and more succinctly below, has been presented and discussed by myself during numerous round-tables, lectures and mini-courses at various congresses organized by the Brazilian Zoological Society (SBZ) and the Brazilian Ornithological Society (SBO); further courses and lectures have been given also by my former students Luis dos Anjos and Alexander Aleixo. So, it can be said that the method is well known in Brazil, but, unfortunately, few ornithologists are willing to learn carefully all the bird vocalizations in their area and to follow strictly the census rules.

\section{METHODOLOGY}

Our methodology is based on the principle of "unlimited-radius spot-censuses" (see Ralph \& Scott 1981). After tests of efficiency, we established the duration of each spot-census or point census as 20 minutes; trial counts over shorter times revealed that inconspicuous and rare species, which are common in tropical forests, were under-estimated. The location of the points used for these censuses should be randomly chosen and representative of the whole area: for each sample, the point must be sorted independently among previously determined points covering the whole area. These points can be marked at given intervals, using a topographic grid or a previously established progression along available trails; points need to be at least $200 \mathrm{~m}$ apart to avoid overrepresentation of species with long-range voices, as we often observed.

The advantages of this censusing method are that:

1) it can be easily adjusted to local conditions;

2) it allows for the repetition of a relatively high number of samples.

The first advantage is critical in areas with difficult locomotion of the observer, as is the case in tropical forests; in fact, the easiest way proved to be to open trails and mark them at $200 \mathrm{~m}$ intervals, thus eliminating the risk to get lost and reducing the time spent between the randomly selected points. 
However, it is also possible to use existing trails, taking care to establish the points for censuses in some random and representative manner.

The second advantage proved decisive for the success of our methodology in tropical forests: because bird species show an asynchronous rhythm of activity, both during the day and along the seasons, one needs to spread the censuses along the whole year and to increase as much as possible the size of the sample. As each of these samples is obtained in a short time (20 minutes plus the time for moving to the next spot), 5 or 6 samples can be obtained easily during one morning period and repeated in different months. We tested and found, at least in São Paulo State, that the highest efficiency is obtained by censusing from just before dawn to mid-morning, and repeating it at 2 to 3 -month regular intervals.

During each sample, which consists of an unlimited-radius 20-minute census at a point randomly selected from a grid covering the study area, the observer counts every distinct contact of all species heard and/or seen. Because more than $90 \%$ of the contacts are only auditory, the observer must be well trained to recognize the voices, principally songs and contact calls, of the species present; dubious identification would ruin the results, not only because of the possible misidentifications, but also because the observer loses records for other species. However, it is impossible to remain prepared for any vocalization of every potentially present species: there appear always some unexpected voices, either unusual vocalization of a known species or vocalization of a species not previously registered in the area. An extensive inventory, with emphasis on voice recording and learning, of the bird community to be studied is necessary. Furthermore, the capacity to record unknown voices during the census is quite effective for later identification; this can be done easily today with a DAT-recorder and an electret shot-gun microphone, and will reduce the number of unindentified contacts.

As very few contacts are visual, it is impossible to count individuals. Furthermore, depending on the social organization and spatial distribution typical of each species, it is also impossible to give a predetermined weight for each type of contact. For instance, for a territorial monogamous species a song contact could be attributed to a pair, but what about a lekking species, where several males gather and make no pair-bonds? Thus we decided to count only contacts, not individuals; however, contacts of a given species with the same location around the observer are not counted separately.

For each species a mean number of contacts per sample (i.e. point census) is calculated: this gives the Index of Point Abundance (IPA). Accepting this value as the best estimate of the proportion of each species in the community, we are able to calculate various parameters of that community. It is obvious that the IPA will vary not only with the real abundance of the species, but also with its pattern of activity and distribution. This defines a specific coefficient of detectability, influencing the value of observed IPA. However, if we admit that this coefficient is intrinsic to the species, it can be considered a specific constant, allowing for comparisons between similar communities.

Calculations of the bird community parameters are then possible. The most valuable single measure proved to be the Shannon-Weaver index of diversity $H^{\prime}$, entropy value derived from the mathematical theory of information (Shannon \& Weaver 1949). Calculations can be repeated for any sub-set of data, according to date, environmental conditions or group of species. Similarity between pairs of data sets can be calculated accurately.

During the survey, other bird observations can be made during the intervals between the spotcensuses and in sourrounding habitats. These data will help the observer to know better the local avifauna, making his sampling more efficient. These data should be gathered regularly, by visit and habitat, allowing for the calculation of the frequency of occurence of each species. Such complementary information, obtained with little additional effort, proved very useful for a detailed interpretation of the results of the quantitative censuses. 


\section{RESULTS}

The above table presents some of the results obtained so far using the methodology presented before. For each surveyed area we give some general information on its location, size and vegetation, and (Table I) global values of the point censuses conducted there: number of samples done, species richness (total number of species observed during the point censuses), index of abundance (mean number of contacts per sample, all species combined) and diversity index $H^{\prime}$ (calculated based on natural logarithms).

From north to south, the area for which these data are available are:

\section{Caravelas}

This and the next site are small (about 100 ha each) forest remnants preserved by BahiaSul S.A. Situated in the municipality of Caravelas, Bahia State (BA), the area is surrounded by pastures and eucalypt plantations for tens of kilometers. The vegetation still retains the original aspect of the exuberant table-land forest typical of that section of the Atlantic Forest. Nevertheless, species richness and index of abundance are both very low, about half of the values found in continuous tracts of the Atlantic Forest farther south (see Saibadela, Carmo and Palmeiras below), where expected diversity should even be lower. In spite of that loss, obviously due to fragmentation and isolation, the value of the index of diversity $H^{\prime}$ remained high.

\section{Pedro Canário}

Another forest remnant maintained by BahiaSul S.A. in the municipality of Pedro Canário, Espírito Santo State (ES), nearly $100 \mathrm{~km}$ to the south, it differs from the preceding one by its more altered vegetation and its continuity with a much larger forest reserve. Despite these differences, the overall bird community parameters are very similar: species richness and diversity are slightly higher, but abundance not.

\section{BROTAS}

The study was done in two small riparian forest fragments at the Jacaré-Pepira river, in the interior of São Paulo State (SP). This site, Santa Elisa in the municipality of Brotas, has an area of 37 ha for a length of $1.250 \mathrm{~m}$, and is surrounded by humid and cultivated habitats. Abundance is very low, richness is low, but diversity is maintained at a good level. More data are needed to understand the pattern of this type of bird community.

\section{DOURADO}

This fragment, Morro Chato, is similar to the previous one. With an area of 27 ha for a length of $1.000 \mathrm{~m}$, it is located in the nearby municipality of Dourado (SP). Community parameters are similar to the previous area, confirming that pattern. Nevertheless, species richness and abundance are higher, whilst diversity is lower.

\section{Lençóis Paulista}

This was the first study undertaken using the presently adopted methodology; it was conducted in 1984-86 (Vielliard \& Silva 1990a) and supplemented in 1987-89 (Vielliard \& Silva 1990b) in a large (592 ha) remnant of the Planalto Paulista forest, preserved by Duratex S.A. in the municipality of Lençóis Paulista, São Paulo State (SP). The area is located in the middle of São Paulo State, far away from the main block of Atlantic Forest, though linked to other natural habitat, principally galleryforests. Species richness and index of diversity are higher than in other fragments like Santa Genebra, but not quite as high as in large tracts of forest like Saibadela or Carmo (see below).

\section{Santa Genebra}

This is a medium-sized (251 ha) remnant of the Planalto Paulista forest, in the municipality and near the city of Campinas, São Paulo State (SP). Although nearer the Atlantic Forest than Lençóis Paulista, it is much more isolated, being located in a suburban zone. This would account for its lower richness and 
TABLE I

Community parameters of Brazilian Atlantic Forest Birds

\begin{tabular}{l|c|c|c|c|l}
\hline Area & $\begin{array}{c}\text { Nr. of } \\
\text { samples }\end{array}$ & $\begin{array}{c}\text { species } \\
\text { richness }\end{array}$ & $\begin{array}{c}\text { index of } \\
\text { abundance }\end{array}$ & $H^{\prime}$ & Reference \\
\hline Caravelas, BA & 30 & 77 & 12.87 & 3.90 & Vielliard \& Silva 1996 \\
Pedro Canário, ES & 30 & 85 & 12.67 & 4.06 & Vielliard \& Silva 1996 \\
Brotas, SP & 110 & 69 & 7.54 & 3.67 & Almeida et al. 1999 \\
Dourado, SP & 110 & 75 & 10.06 & 3.53 & Almeida et al. 1999 \\
Lençóis Paulista, SP & 170 & 129 & 19.59 & 3.92 & Vielliard \& Silva 1990a,b \\
Santa Genebra, SP & 202 & 96 & 23.52 & 3.68 & Aleixo \& Vielliard 1995 \\
Boracéia, SP & 192 & 173 & 24.27 & 4.40 & Stotz, in prep. \\
Saibadela, SP & & & & & Aleixo 1996, 1997 \\
$\quad$ unexploited & 163 & 142 & 25.21 & 3.99 & \\
$\quad$ exploited & 142 & 143 & 26.94 & 4.09 & \\
Carmo, SP & 90 & 139 & 24.31 & 4.43 & Vielliard \& Silva, in press \\
Palmeiras, PR & & & & & Anjos 1992 \\
$\quad$ 1.000 ha & 72 & 138 & 26.83 & 4.37 & \\
$\quad 40$ ha & 62 & 125 & 18.85 & 4.23 & \\
$\quad$ 20 ha & 72 & 103 & 22.14 & 4.11 & \\
9 9 ha & 72 & 91 & 25.74 & 4.01 & \\
Salto Piraí, SC & 190 & 102 & 7.34 & 4.08 & Machado 1996
\end{tabular}

diversity, but the abundance is quite high.

\section{BORACÉIA}

This location corresponds to the highest part of the Atlantic Forest on the coastal ridge in northern São Paulo State (SP), near the municipality of Salesópolis. Abundance and diversity are both very high, and richness, even taking into account the large number of samples, is the highest recorded so far in the Atlantic Forest. Results need to be published in details for thorough evaluation.

\section{SAIBADELA}

This site corresponds to the lower part of the Atlantic Forest on its inland southern ridge in São Paulo State. Two areas have been sampled in order to evaluate the effect of past selective exploitation of part of this very large tract of forest, belonging (as the next site, Carmo) to the Fazenda Intervales Reserve between the municipalities of Capão Bonito and Eldorado.
Richness, abundance and diversity are high, in accord with the extraordinary biodiversity of the region. Differences between the natural and exploited plots are globally insignificant, certainly because the latter suffered only minor disturbance and remained in direct contact with the large natural forest, but sensitive species can be affected.

\section{CARMO}

This is the medium-elevation part of the Atlantic Forest in the same large tract of preserved forest as "Saibadela". Richness and abundance are quite similar to those of the unexploited Saibadela and continuous Palmeiras forest communities, but diversity is the highest registered so far.

\section{PALMEIRAS}

The study was conducted in a continuous tract and three small natural "islands" of the Planalto forest in the State of Paraná (municipality of Palmeiras, 
PR), not very far from the Atlantic Forest. Richness, abundance and diversity were found to be all remarkably high in the continuous forest, reflecting the outstanding natural biodiversity of the region. These values are appreciably lower in the very small natural "islands" of forest scattered in the surrounding "campos". Richness and diversity decreased with the size of these "islands", but abundance proved to be inversely proportional to their size. More data are needed to explain these variations.

\section{Salto Piraí}

This is an area of 1.332 ha of Atlantic Forest, part of a larger reserve in the municipality of Joinville, Santa Catarina State (SC). Species richness is probably lower than in similar areas in the north for biogeographical reasons. Abundance is astonishingly low for no clear reason. However, diversity shows a good level. Comparisons with other data from the southern part of the Atlantic Forest would help understand its bird community parameters.

\section{CONCLUSIONS}

The results succinctly presented here permit to conclude that:

1) our methodology of point censusing proved to be efficient for collecting representative data in the field without disturbance;

2) the data obtained permit accurate calculations of community parameters such as index of diversity, index of abundance, and similarity;

3) the values obtained so far are coherent with environmental conditions of the areas surveyed, but indicate also some unexpected deviations;

4) a common data-base should be organized and enlarged with further surveys in new areas and habitats;

5) where possible, new sampling in a given area will test the potential of the survey for medium and long-term monitoring;
6) more detailed analyses need to be published quickly to provide data for better local and regional conservation policies.

\section{ACKNOWLEDGEMENTS}

The results here presented have been obtained through the support of the Brazilian Academy of Sciences-ABC, National Council of Research$\mathrm{CNPq}$, Foundation $\mathrm{MB}$, and with the contributions of Duratex S.A. for the methodology testing and first survey in its area in Lençois Paulista, BahiaSul S.A. for the survey in its areas in Caravelas and Pedro Canário, Federal and State agencies (IBAMA, Fundação Florestal, and others) for areas under their care, Post-Graduate programs of public universities (UNICAMP, USP and UFPR) for sustaining participating students, Brazilian scientific societies (SBZ, SBO and others) for promoting the methodology, numerous colleagues for their participation, and Dr. Keith Brown for discussing and revising the manuscript.

\section{REFERENCES}

Aleixo A. 1996. Impacto da extração seletiva de espécies arbóreas sobre uma comunidade de aves da Mata Atlântica. Resumos V Congr. Bras. Ornit., Campinas, p. 1.

Aleixo A. 1997. Estrutura e organização de comunidades de aves em áreas de Mata Atlântica primitiva e explorada por corte seletivo. Unpubl. MSc. Dissertation, UNICAMP, Campinas, IX + 78 p.

Aleixo A \& Vielliard J. 1995. Composição e dinâmica da avifauna da mata de Santa Genebra, Campinas, SP. Revta bras Zool 12: 493-511.

Almeida ME, Vielliard J \& Dias MM. 1999. Composição da avifauna em duas matas ciliares na bacia do rio Jacaré-Pepira, São Paulo, Brasil. Revta bras Zool 16: 1087-1098.

Anjos L. 1992. Riqueza e abundância de aves em "ilhas" de florestas de Araucária. Unpubl. Ph.D. Thesis, Univ. Fed. do Paraná, Curitiba. XVI + 162 p.

Barbosa AF. 1992. Avifauna de uma mata de Arau- 
caria e Podocarpus do Parque Estadual de Campos do Jordão, São Paulo. Unpubl. MSc. Dissertation, USP/ESALQ, Piracicaba. XVI + 173 p.

BiERREgAARD ROJr \& LOVEJOY TE. 1989. Effects of forest fragmentation on Amazonian understory bird communities. Acta Amazonica 19: 215-241.

Blondel J, Ferry C \& Frochot B. 1970. La méthode des indices ponctuels d'abondance (I.P.A.) ou des relevés d'avifaune par "stations d'écoute". Alauda 38: $55-71$.

Brown KS. 1986. Zoogeografia da região do Pantanal mato-grossense. In: Anais $1^{\circ}$ Simpósio sobre Recursos Naturais e Sócio-econômicos do Pantanal. EMBRAPA: Brasília. p. 137-178.

HAFFer J. 1974. Avian speciation in tropical South America. Publ. Nuttal Ornith. Club 14, Cambridge, Mass.

Kettle R. 1989. Major wildlife sound libraries. Bioacoustics 2: 171-175.

Machado DA. 1996. Estudo de populações de aves silvestres da região do Salto Piraí, Joinville, SC. Unpubl. MSc. Dissertation, USP/ESALQ, Piracicaba. $\mathrm{XIII}+151 \mathrm{p}$.

Prum RO. 1994. Species status of the White-fronted Manakin, Lepidothrix serena (Pipridae), with comments on conservation biology. Condor 96: 692702 .

RalPH CJ \& ScOTT JM. (Ed.) 1981. Estimating Numbers of Terrestrial Birds. Cooper Ornithological Society. Studies in Avian Biology 6: 630 p.
Shannon CE \& Weaver W. 1949. The mathematical theory of communication. Univ. Illinois Press: Chicago, USA.

Stotz DF, FitzPatrick JW, PARker TA \& Moskovits DK. 1996. Neotropical Birds: Ecology and Conservation. Univ. of Chicago Press, Chicago, Ill.

Stouffer PC \& BierregaArd ROJR. 1995. Use of Amazonian forest fragments by understory insectivorous birds. Ecology 76: 2429-2445.

Toledo MCB DE. 1993. Densidade e distribuição da avifauna de duas reservas fragmentadas de Mata Atlântica na Serra da Mantiqueira, SP. Unpubl. MSc. Dissertation, USP/ESALQ, Piracicaba. XIII + 112p.

Vielliard J \& Silva ML DA. 1996. Effect of forest fragmentation on bird communities in coastal Brazil. Southern Hemisphere Ornithological Congress. $A b$ stracts... Albany, Australia: RAOU, 1996. 1: 50-51.

Vielliard J \& Silva WR. 1990a. Nova metodologia de levantamento quantitativo e primeiros resultados no interior do estado de São Paulo. Anais ENAV, UFRPe, Recife, 4: 117-151

Vielliard J \& Silva WR. 1990b. Censusing neotropical forest bird communities: first results from São Paulo State, Brazil. Acta XX Intern. Ornith. Congress, Suppl., Christchurch, New Zealand, p. 462.

Vielliard J \& Silva WR. in press. Avifauna. In: Fundação Florestal; Intervales. São Paulo, p. 122-141. 